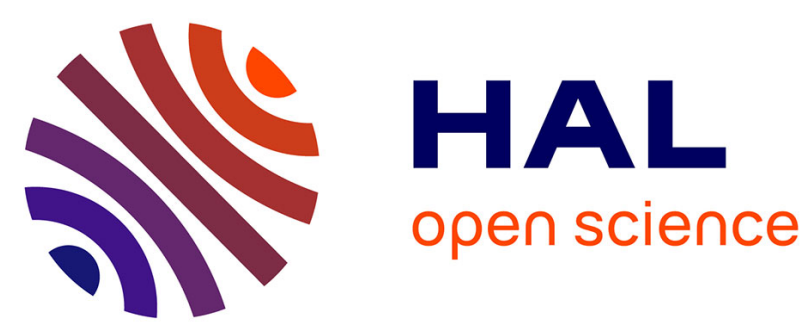

\title{
A novel identification method for obtaining bending moment-curvature relations of wood stems based on digital image correlation and SDOF analysis
}

David Bertrand, Nicolas Tardif, Franck Bourrier, Jean-Baptiste Barre, Stéphane Grange

\section{To cite this version:}

David Bertrand, Nicolas Tardif, Franck Bourrier, Jean-Baptiste Barre, Stéphane Grange. A novel identification method for obtaining bending moment-curvature relations of wood stems based on digital image correlation and SDOF analysis. European Journal of Environmental and Civil Engineering, 2022, 25 (10), pp.1782-1795. 10.1080/19648189.2019.1602567 . hal-02094497

\section{HAL Id: hal-02094497 \\ https://hal.science/hal-02094497}

Submitted on 12 Jun 2019

HAL is a multi-disciplinary open access archive for the deposit and dissemination of scientific research documents, whether they are published or not. The documents may come from teaching and research institutions in France or abroad, or from public or private research centers.
L'archive ouverte pluridisciplinaire HAL, est destinée au dépôt et à la diffusion de documents scientifiques de niveau recherche, publiés ou non, émanant des établissements d'enseignement et de recherche français ou étrangers, des laboratoires publics ou privés. 


\title{
A novel identification method for obtaining Bending Moment-Curvature relations of wood stems based on Digital Image Correlation and SDOF analysis.
}

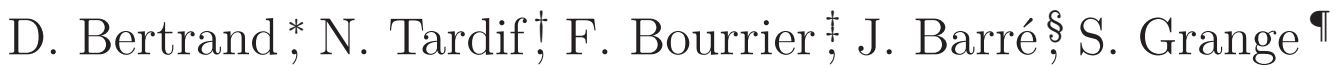 \\ 12 juin 2019
}

\begin{abstract}
Résumé
Bending Moment-Curvature relations $(\mathrm{M}-\chi)$ are useful in many beam modeling approaches. It allows describing in a simple way the mechanical behavior at the cross-section scale and can be used to model continuous beams as single degree of freedom systems dedicated to perform stochastic analysis. This paper focused on tree mechanical charaterization and presents an identification method for obtaining bending moment - curvature relationships up to failure from Digital Image Correlation (DIC) and experimental three points bending tests. Due to wood intrinsic variability, the proposed identification method has been validated from a Finite Element (FE) model which aims at simulating precisely the bending response of a cylindrical stem. The refined FE model has been developed based on the geometry and the boundary conditions of the experimentally tested stems. M- $\chi$ curves are derived from the FE model and used within a Single Degree Of Freedom (SDOF) approach. At the stem scale, the prediction of the SDOF model (Force-Displacement) is compared to the FE model and lead to a good agreement. Then the approach is used to characterize fresh
\end{abstract}

*Assistant Professor, david.bertrand@insa-lyon.fr - INSA Lyon / GEOMAS Lab., 34 avenue des arts, 69621 Villeurbanne Cedex, France

${ }^{\dagger}$ Assistant Professor - INSA Lyon - INSA Lyon / LAMCOS Lab., 34 avenue des arts, 69621 Villeurbanne Cedex, France

${ }^{\ddagger}$ Research fellow- Irstea Grenoble - Univ. Grenoble Alpes, Irstea, LESSEM, 38000 grenoble, France

${ }^{\S}$ PhD Student - Irstea Grenoble - Univ. Grenoble Alpes, Irstea, LESSEM, 38000 grenoble, France

`Professor - INSA Lyon - INSA Lyon / GEOMAS Lab., 34 avenue des arts, 69621 Villeurbanne Cedex, France 
European beech samples allowing deriving their mechanical properties (longitudinal Young modulus, modulus of elasticity and modulus of rupture).

\section{Introduction}

M- $\chi$ relations are useful in many beam modeling approaches which allow describing in a simple way the mechanical behavior at the crosssection scale accounting for potential material non linearities. Knowing M- $\chi$ relation, Mass-Spring equivalences, also called SDOF (Single Degree Of Freedom) equivalences, can be performed. Thus, continuous beams can be modeled as single degree of freedom systems (a single mass connected to a nonlinear spring) and thus could be used in many applicative fields of mechanics and especially when stochastic analysis should be performed. Given the boundary conditions and the loading, the static and dynamic response of the overall system can be simulated with a very good accuracy for a very low computational time.

This paper focused on tree mechanical charaterization. Due to wood intrinsec variability, $\mathrm{M}-\chi$ relations allow describing the mechanical behavior of the stem from a macroscopic, i.e. averaged, point of view (cross-section scale) and thus reduce apparent variability. This paper presents an identification method for obtaining bending moment - curvature relationships up to failure from Digital Image Correlation (DIC) and experimental three points bending tests.

Detailed wood mechanical behavior assessment is mandatory in order to explore tree responses when subjected to various loadings such as own weight, wind or snow. Such research works are also essential to provide experimental data (Moore (2000), Lundstrom et al. (2008), Wessels et al. (2011)) and models (Sellier et al. (2006), Dupuy et al. (2007), Hu et al. (2008), Bentaher et al. (2013)) for latter use in more applied fields : tree response to wind (James et al. (2006)), natural hazards (Dorren et al. (2006)), outdoor structures (Fragiacomo (2006)), manufacturing processes (Thoemen and Humphrey (2003)), quasi static (Alméras et al. (2002)) or dynamic loadings (Bertrand et al. (2013)) etc. The mechanical properties of wood depend on many parameters (moisture content, wood species and age, defects, decay state, micro structure, etc.) and on the scale of the experimental sample. Even if recent studies proposed innovative methodologies based on strain field analysis (Haldar et al. (2011)), wood mechanical properties derivation from experiments performed at the sample scale (Forsberg et al. (2010)) is difficult to use at the stem or tree scale because no clear relations exist yet between micro (fiber or group of fiber) and macro structure. As a consequence, the experiment set up has to be adapted to the scale of study $(\mathrm{mm}, \mathrm{cm}, \mathrm{m}, \mathrm{dm})$. In the case of stem or tree scales, 
metric (Ruel et al. (2010), Lundstrom et al. (2007)) and decametric (Moore and Maguire (2005), Ciftci et al. (2014), Sebera et al. (2014)) experimental tests are undertaken to assess properties such as $\sigma_{e}$ (modulus of elasticity), MOR (modulus of rupture) or natural frequencies of the structure from a macroscopic point of view. For instance, swaying tests (Milne (1991)) and three (Herajarvi (2004), Ruel et al. (2010)) or four (Brancheriau et al. (2002)) points bending tests are widely used. However, these experiments are not always easy to carry out in particular when wood stem has no cylindrical cross-section and/or defects along the longitudinal axis (Murphy (2000), Lundstrom et al. (2007)). In these cases, the local curvature can be tricky to measure accurately up the failure of the stem.

The context of this work belongs to the characterization of trees subjected to rockfalls. When wooded terrains are considered, forest is recognized as an efficient rockfall protection (Dorren et al. (2004)). In addition, innovative protective structures made of felled trees are used as protection dikes so-called protection felled trees (PFT) structures (Olmedo et al. (2015)). The design of PFT structures is performed by using rock propagation codes (Berger and Dorren (2006)) to assess the runout distance of the blocks. Within the context of natural hazards, stochastic approaches are needed to assess the size of the affected zone and thus effective numerical models in terms of CPU time are mandatory (Bourrier et al. (2009)). Based on Biggs (1964) researches, single degree of freedom (SDOF) models can be proposed in order to represent the interaction between the block and a tree stem. The approach has been already used with success within the rockfall context (Schellenberg (2008), Schellenberg et al. (2011), Bertrand et al. (2015)). Because of their low CPU time cost, the latter can be used for the modeling of PFT structures within a stochastic framework involving many trajectographic simulations. In the context of the study, the stem is simply supported and impacted at mid-span, which corresponds to classical configuration for PFT structures (Olmedo et al. (2015)). The dynamic part of the motion is only related to the equivalent mass and the static part is related to the bending stiffness of the stem. Material non linearities are accounted through the stiffness reduction which is function of the loading magnitude. The stiffness of the system is directly related to the $M-\chi$ curve that exhibits the stem. Once the $M-\chi$ curve of the stem is obtained, SDOF equivalences can be performed for a wide range of boundary conditions and thus can be used for many scenarii of loadings.

The article presents an identification method that makes it possible to obtain the $M-\chi$ curve of a piece of green wood (water content above the fiber saturation point) with a geometry that can be assimilated to a beam. The method is based on Digital Image Correlation (DIC) and experimental three points bending tests. DIC provides the displace- 
ment field of the longitudinal axis developed by the stem during the loading process and thus allows the curvature of the entire stem to be accurately described as well as in a narrow area of the structure (typically where the "plastic" hinge occurs).

In the first part, the experimental protocol is described. Secondly, the identification method is exposed. Then the SDOF equivalence technics is presented in the case of 3 points bended beams. Particular attention is paid to how the macroscopic response of the system (expressed in terms of Force-Displacement curve) is derived from the M- curve, the beam geometry and boundary conditions. Next, due to the high variability of wood properties and in order to have a perfect control on all the inputs parameters (geometrical and mechanical parameters of the stem), the validation of the method is performed using a refined Finite Element (FE) model of an idealized stem. The results provided by the FE model are compared (in terms of Force-displacement response) to the results of the SDOF where the M- $\chi$ curve is deduced from the displacement field of the FE model and then injected into the SDOF model. In order to be as close as possible to the experimental bending test, the FE model accounts for the main physics involved during the experimental test (large displacements, contact at support with finite sliding, non-linear material behavior in particular).

In order to estimate the accuracy of the M- $\chi$ identification method, a sensitivity analysis is carried out exploring the effect of the polynomial order and the continuity degree of the fitting functions. Finally, the identification method is applied on green wood stems in order to derive $M-\chi$ curves and the SDOF prediction is compared to the experimental results in terms of Force-Displacement response. From these results, rheological parameters are assessed such as the longitudinal Young modulus $\left(E_{L}\right)$, the modulus of elasticity $\left(\sigma_{e}\right)$ and the modulus of rupture (MOR).

This novel experimental identification method allows assessing the M- $\chi$ relationship of wooden beam (but not only) reducing the intrinsic wood variability by an averaged description of the response at the scale of stem. It allows the user getting a macroscopic characterization where elastic and nonlinear response is simply integrated at the cross section scale. The derived data are ready to use within $\mathrm{M}-\chi$ based models (such as SDOF or beam finite elements). 


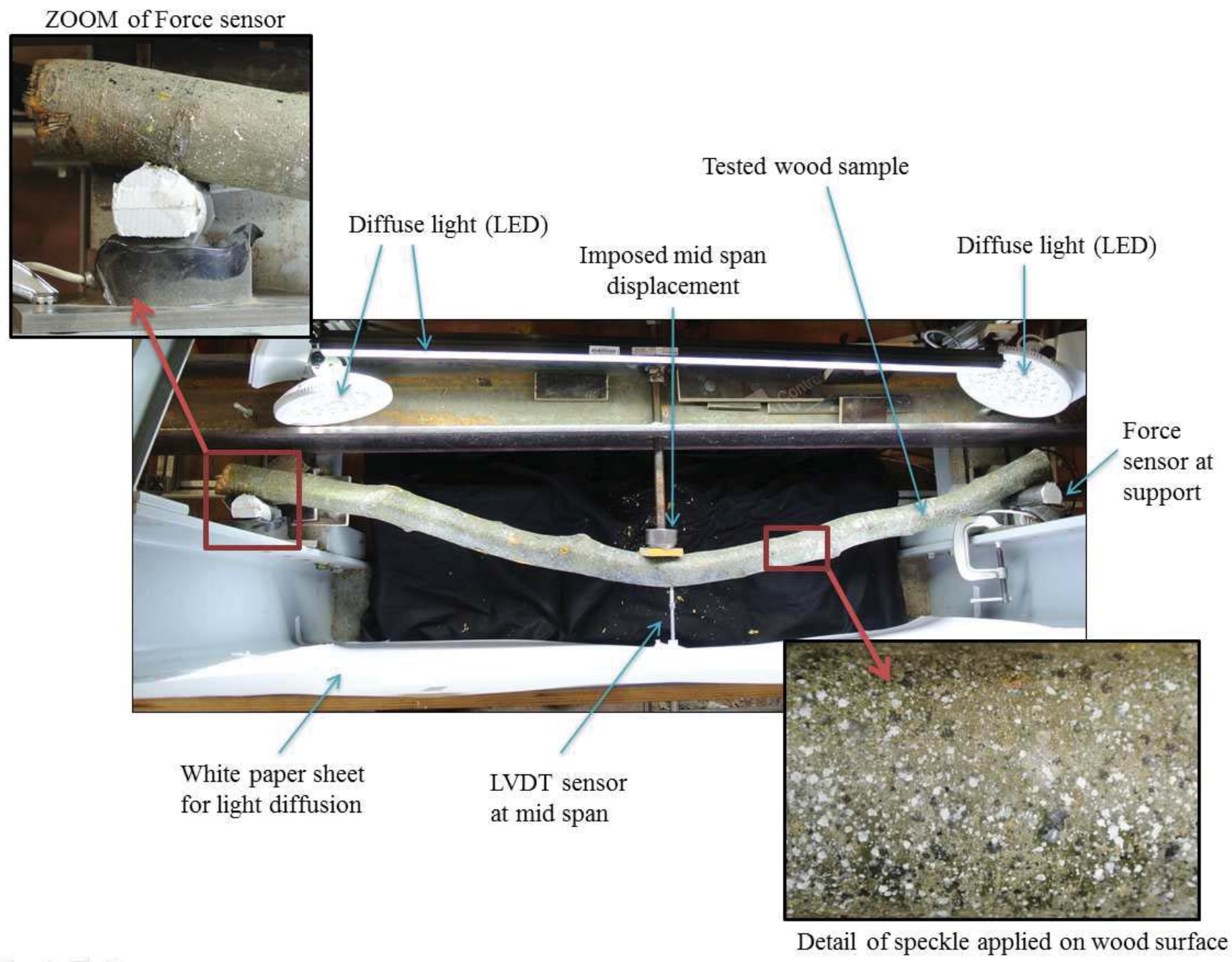

FiguRE 1 - Scheme of the three points bending test with force sensors and camera positions (a). Experimental device used for the three points bending test (b). 


\section{Materials and methods}

\subsection{Quasi-Static bending tests}

\subsubsection{Experimental set up}

Quasi-static bending tests were performed on stems. The experimental device is depicted in Figure 1 where a stem under three point bending is shown. The tests consist in imposing a displacement at mid span and to measure the reaction forces (Siscam MC $100 \mathrm{kN}$ sensor linearity $<0.15 \%$ ) and the mid span displacement (LVDT sensor from SolartronMetrology, S serie, range $100 \mathrm{~mm}$ and linearity $<0.2 \%$ ). The acquisition frequency was $0.05 \mathrm{~Hz}$ thus a measure of forces at supports and an image were recorded every 20 s and the test duration was about $25 \mathrm{~min}$ in average. In addition, a Pike F-1100B camera combined with Xenon-Emerald 28/2.8-F-L lens was located above the specimen in order to take successive pictures of the deformed beam. The resolution of the cameras is $4008 \times 2672$ pixels. The ratio $\mathrm{mm} /$ pixels was about $2.27 \mathrm{~mm} /$ pixel. A random gray level pattern was achieved by spraying high temperature matte black and white paints on the surface of the wood in order to perform DIC analysis. A LED light system has been used to enhance the speckle contrast (Meta Bright Exolight ISO-4 (165,000lux) / 58W (24VDCx2.4A), white color 5500K). The typical theoretical error in the DIC technique is \pm 0.02 pixels. Using this setup, the measurement is found to have displacement resolution of $0.04 \mathrm{~mm}$. The commercial software VIC2D (Vic2D-2009-x86) allows performing the DIC and deducing the evolution of the displacement field during the test up to the failure of the beam.

\subsubsection{Tested Stems}

All trees came from the Col de Vence forest in France (Rhône Alps region Lat. $45^{\circ} 45^{\prime}$, Long. $\left.5^{\circ} 45^{\prime}\right)$ and the species was European beech (Fagus sylvatica), one of the most common hardwood in the Alps. The stems selection was carried out to get similar geometries between each stem avoiding as much as possible defects such as knots, conicity or lack of straightness.

In order to keep the wood moisture content above the fiber saturation point, stems were tested no later that one day after harvest. During this period, the stems were put in plastic bag to lower the evaporation process. The length of the stems was $1.70 \mathrm{~m}$ and the mean diameters were between $60 \mathrm{~mm}$ and $90 \mathrm{~mm}$. The span between supports of the bending test apparatus was $150 \mathrm{~cm}$. In this paper, 13 stems have been used and Table 1 gives the mean diameters. 


\begin{tabular}{|c|c|c|c|c|}
\hline $\begin{array}{c}\text { Tested } \\
\text { stem }\end{array}$ & $\begin{array}{c}\phi_{\text {mean }} \\
(\mathrm{mm})\end{array}$ & $\begin{array}{c}E_{L} \\
(\mathrm{MPa})\end{array}$ & $\begin{array}{c}\sigma_{e} \\
(\mathrm{MPa})\end{array}$ & $\begin{array}{c}\text { MOR } \\
(\mathrm{MPa})\end{array}$ \\
\hline 1 & 69.7 & 15694 & 42.1 & 74.3 \\
2 & 79.0 & 9962 & 33.0 & 64.0 \\
3 & 67.3 & 6848 & 33.4 & 55.1 \\
4 & 78.7 & 10115 & 33.4 & 65.8 \\
5 & 79.0 & 9298 & 33.0 & 61.5 \\
6 & 60.3 & 6744 & 29.2 & 50.2 \\
7 & 74.3 & 11936 & 37.2 & 77.9 \\
8 & 52.3 & 9610 & 42.7 & 76.2 \\
9 & 69.7 & 9038 & 48.8 & 76.4 \\
10 & 90.3 & 10942 & 34.5 & 63.6 \\
11 & 60.0 & 8383 & 37.7 & 58.9 \\
12 & 71.7 & 9359 & 46.9 & 76.8 \\
13 & 80.7 & 7389 & 38.8 & 66.7 \\
\hline
\end{tabular}

TABLE 1 - Mean diameters $\left(\phi_{\text {mean }}\right)$, longitudinal Young modulus $\left(E_{L}\right)$, elastic stress limit $\left(\sigma_{e}\right)$ and modulus of rupture (MOR) of the tested stems.

\section{$2.2 \quad$ M- $\chi$ relationship assessment}

The flowchart of the identification method is proposed in Figure 2a. Taking successive photographs of the deformed beam allows measuring the displacement field at the surface of the cylindrical beam. Thus the deflection $y(x)$ can be obtained as a function of the imposed displacement (Figure 3a).

In term of beam structural response, during the loading two main phases can be identified. For small displacements, the material stays in the elastic domain. Thus, because the bending moment is linear along the beam, $y(x)$ can be described by a third-order polynomial. Then material non linearities are assumed to develop at mid span where the bending moment is maximum (rupture for fibers in tension, delamination, buckling for fibers in compression, etc.). Under this assumption, the deformations are concentrated at mid span and two almost straight lines are separated by a kind of "plastic hinge".

In order to get the relationship between the bending moment and the curvature at mid span, the experimental data coming from DIC analysis are fitted by polynomial interpolation. Three fitting intervals are defined and Figure $3 \mathrm{c}$ gives their respective lengths $\left(L_{1}^{f i t}\right.$ and $\left.L_{2}^{f i t}\right)$. The latter allow describing the curvature of the "plastic" hinge zone. Then experimental points of the deflection $(y(x))$ are fitted on each interval by polynomial interpolation. The polynomial order can be chosen 


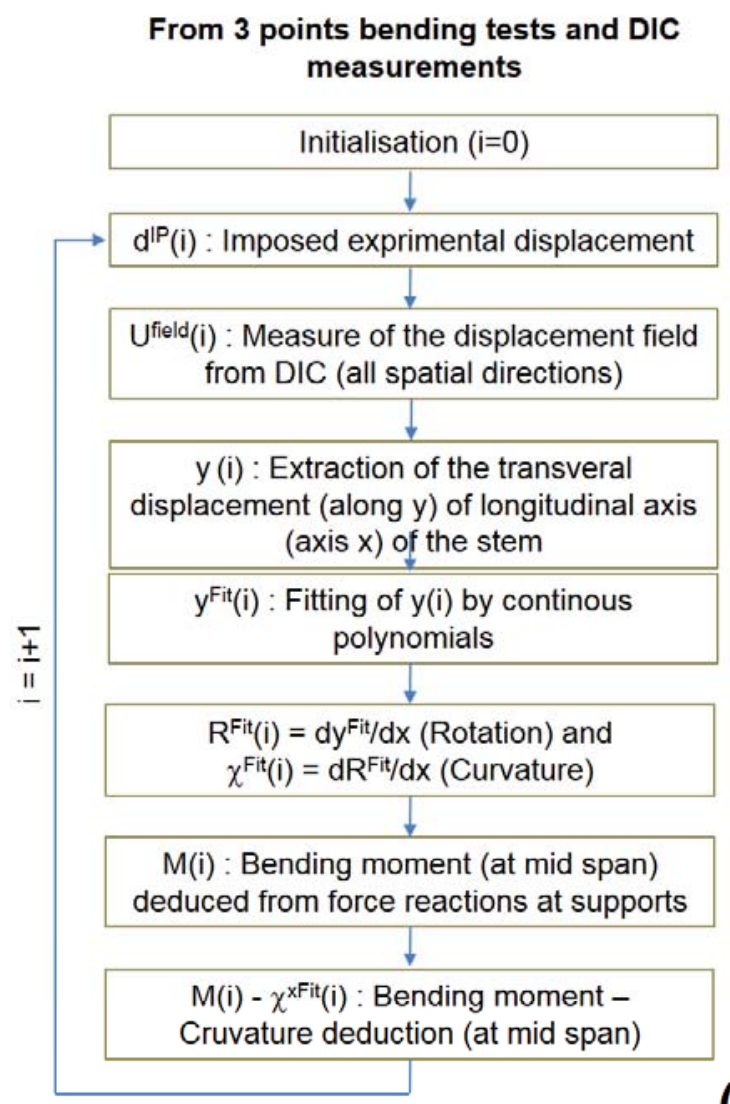

Validation SDOF / FE Model

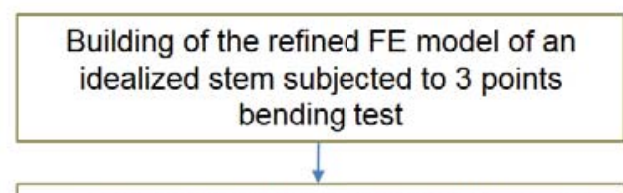

- Extraction of the transversal (along y) displacements of the longitudinal axis of the stem

- $M-\chi$ deduction (at mid span) based on the proposed identification method

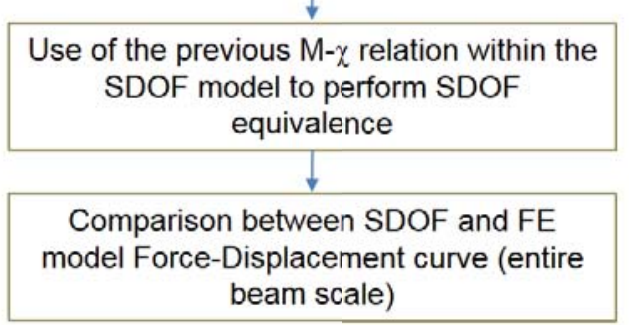

(b)

Figure 2 - Main steps of the identification method allowing deducing the $\mathrm{M}-\chi$ curve from 3 points bending test and DIC measurements (a). Validation methodology of the identification method (b). 

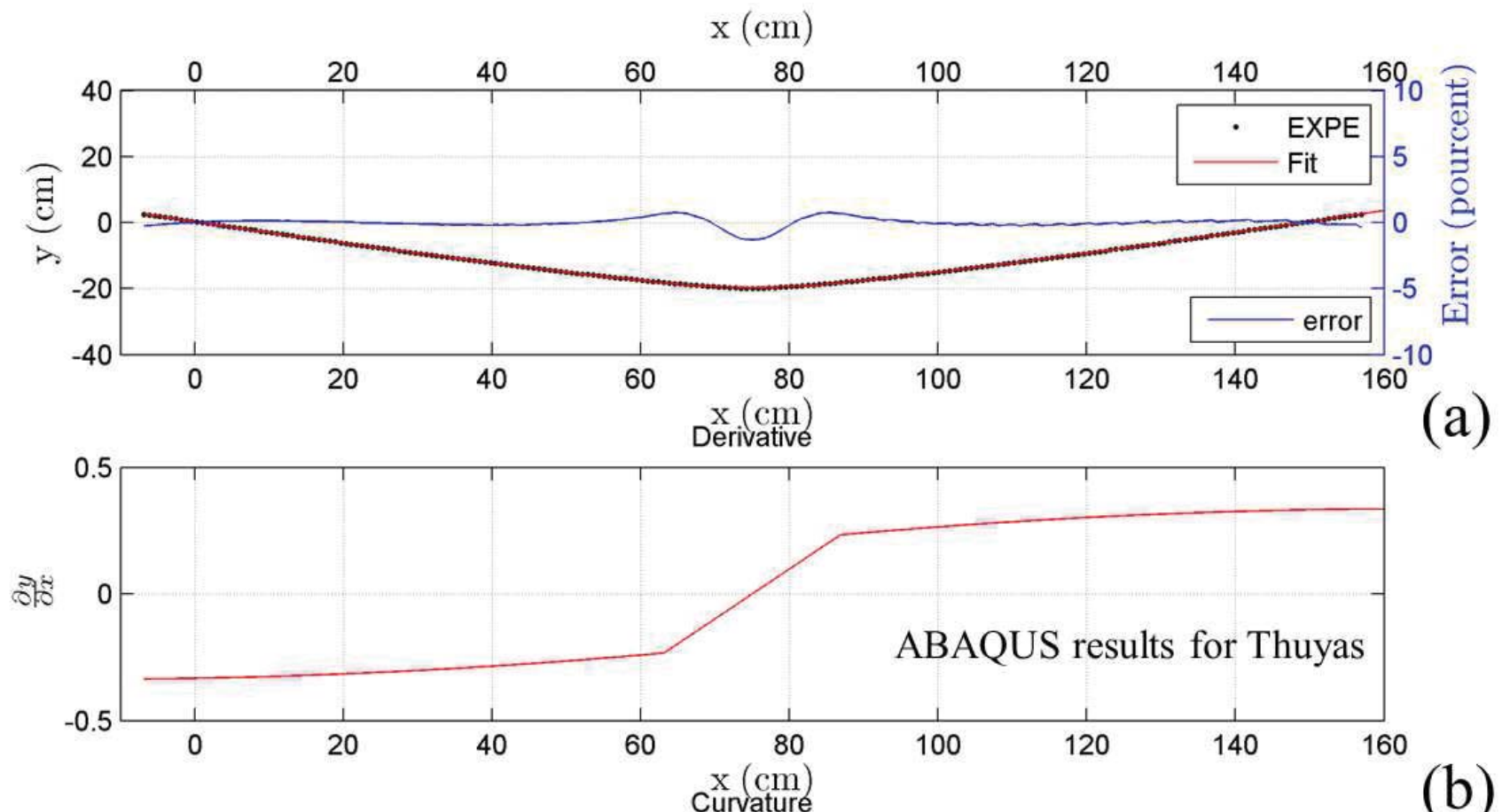

(b)

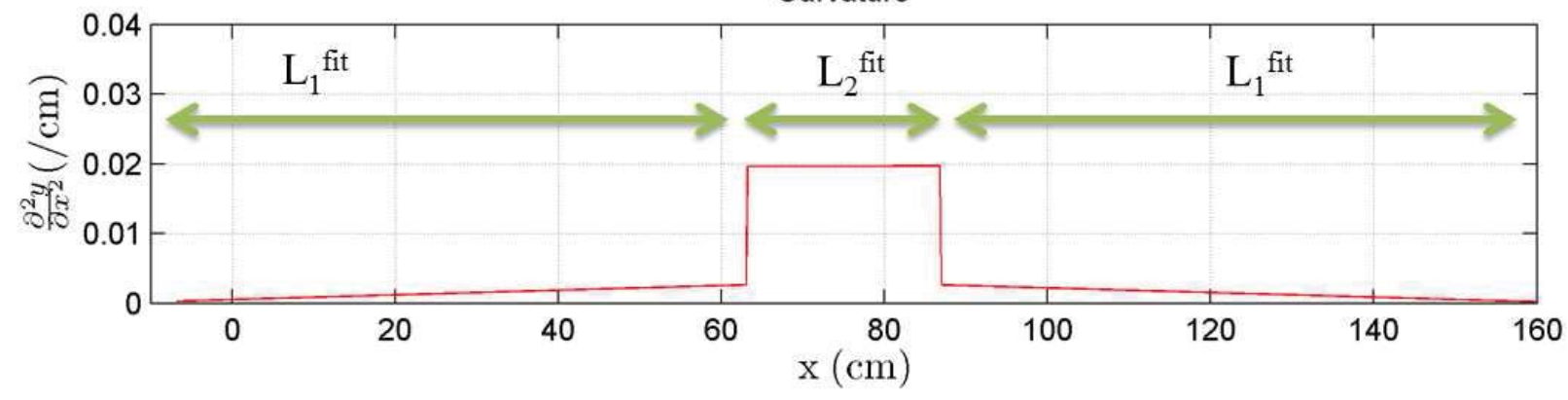

(c)

Figure 3 - Example of curvature derivation (c) from displacement field $y(x)$ (a) in the case of an imposed displacement of $20 \mathrm{~cm}$. The error is defined such as $\xi=\frac{X_{i}^{f i t}-X_{i}}{X_{i}} \times 100$ where $X_{i}$ are the fitted values and $X_{i}^{f i t}$ are the values of the fit. (b) corresponds to the first derivative of the polynomial fit of the beam deflection. These results correspond to the FE model of thuyas. 


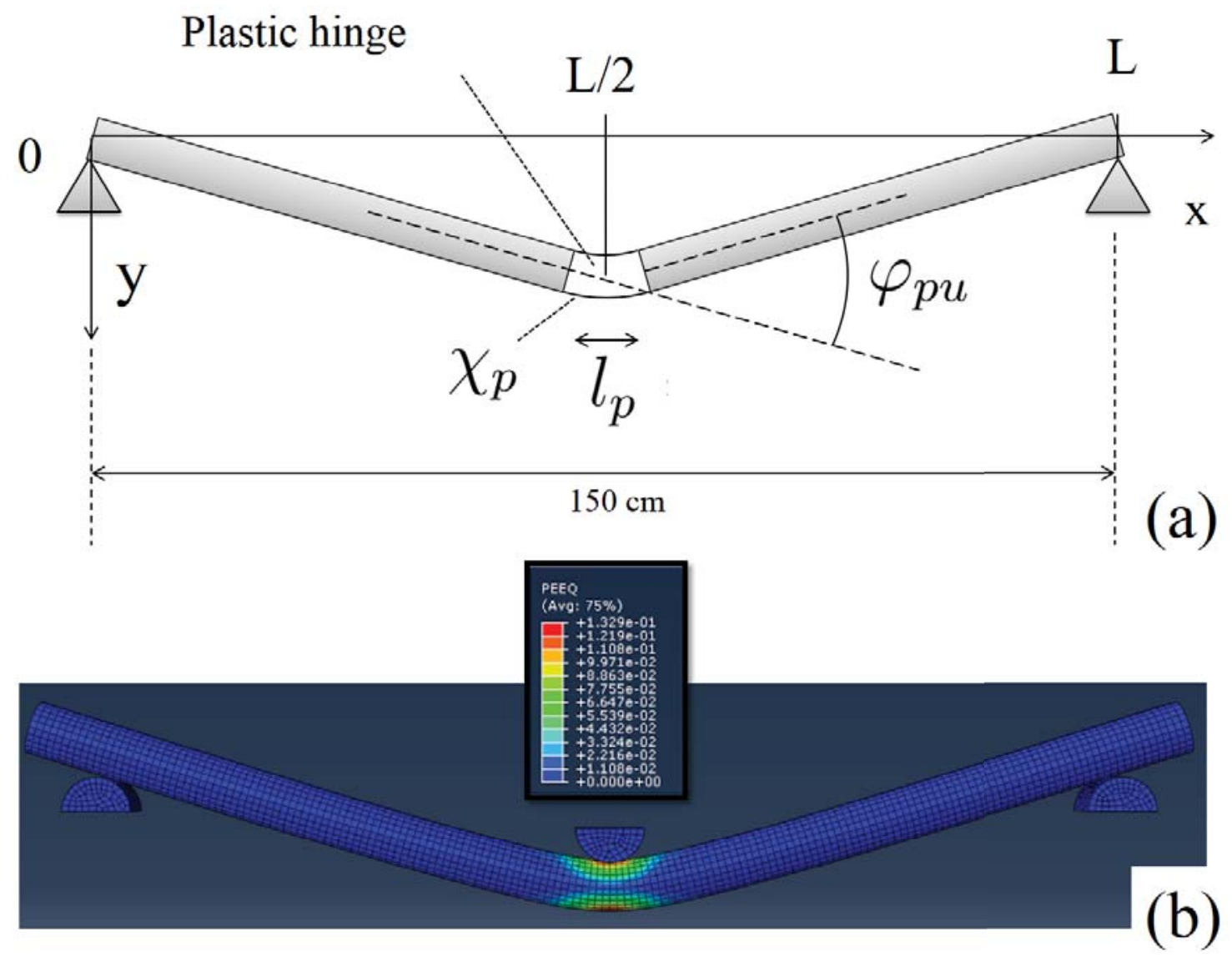

Figure 4 - Schematic view of the SDOF equivalence when the "plastic" hinge has developed (a). FE model of the experiment where the cumulative plastic strain (PEEQ) is depicted allowing locating permanent strains (b).

and also the continuity conditions on $y^{f i t}(x)$ between adjacent intervals. Thus the main parameters of the fit are $L_{2}^{f i t}$, the polynomial order ( $x^{2}$ or higher) and the continuity conditions $\left(C^{o}\right.$ or $\left.C^{1}\right)$ between adjacent polynomials (Tardif and Kyriakides (2012)).

Then the second derivative of the fitted curve allows assessing the curvature at mid span. The bending moment at mid span is deduced from the lever arm and the reaction force at the supports. These method is applied for all photographs and allows obtaining the $M-\chi$ curve.

\subsection{SDOF approach}

A SDOF approach allows relating the displacement of a specific point of the stem (midspan in this case) to the applied force. The evolution of the load-displacement curve of the SDOF model can be deduced from the $M-\chi$ relationship. The yield load $F_{y}$, which corres- 
ponds to the development of material non linearities within wood, is calculated by the relation $M_{y}=\frac{F_{y} L}{4} \leftrightharpoons F_{y}=\frac{4 M_{y}}{L}$ where $L$ is the span between the two supports of the bending device. Next, the associated displacement at mid span $\left(w_{y}\right)$ is deduced from

$$
w_{y}=\frac{F_{y} L^{3}}{48 \bar{K}}
$$

where $\bar{K}=\frac{M_{y}}{\chi_{y}}$ the bending stiffness with $\chi_{y}$, the curvature associated to $M_{y}$. Hence, the " elastic» stiffness of the SDOF model is given by

$$
K_{e l}=\frac{48 \bar{K}}{L^{3}}
$$

Similarly, the ultimate load is estimated in terms of the ultimate moment $F_{u}=\frac{4 M_{u}}{L}$. Assuming that a "plastic" hinge forms at mid-span, the ultimate displacement is $w_{u}=w_{y}+w_{p u}$ where $w_{p u}$ is the total "plastic" displacement. The latter equals $w_{p u}=\frac{\varphi_{p u} L}{4}$ where $\varphi_{p u}$ is the total "plastic" rotation of the cross section (Figure 4a). By assuming the total "plastic" curvature $\left(\chi_{p}\right)$ constant along the "plastic" hinge length $l_{p}$ it comes $\varphi_{p u}=\chi_{p} l_{p}$ where $\chi_{p}=\chi_{u}-\chi_{y}$. The length of the "plastic" hinge is assessed from the experimental three points bending tests and leads to consider $l_{p}=3 \times \phi_{\text {mean }}$ where $\phi_{\text {mean }}$ is the mean diameter of the tested stem. Then the ultimate displacement can be expressed such as

$$
w_{u}=w_{y}+\frac{1}{4}\left(\chi_{u}-\chi_{y}\right) l_{p} L
$$

For a better description of the shape of the M- $\chi$ curve, it can be interesting to consider a trilinear curve to describe the quasi static response of the SDOF. Thus, an additional point is defined under the same previous assumptions. From the M- $\chi$ curve, a point $M_{i-} \chi_{i}$ gives the following mid span displacement $\left(w_{i}\right)$ and force $\left(F_{i}\right)$

$$
\begin{array}{r}
w_{i}=w_{y}+\frac{1}{4}\left(\chi_{i}-\chi_{y}\right) l_{p} L \\
F_{i}=\frac{4 M_{i}}{L}
\end{array}
$$

Finally, two "plastic" stiffnesses of the SDOF model can be defined by

$$
\begin{aligned}
K_{p l}^{1} & =\frac{F_{i}-F_{y}}{w_{i}-w_{y}} \\
K_{p l}^{2} & =\frac{F_{u}-F_{i}}{w_{u}-w_{i}}
\end{aligned}
$$




\subsection{ABAQUS FE model}

Figure $4 \mathrm{~b}$ depicts the FE model (ABAQUS Standard) developed to validate the identification method described in section 2.2. A cylindrical beam has been modeled in 3D. The length of the beam is $170 \mathrm{~cm}$ for a mean diameter $\phi_{\text {mean }}$ of $79 \mathrm{~mm}$. The boundary conditions are represented by three half cylinders. The latter are meshed to take into account the symmetry of the structure. Contact interaction approach based on hard contact with finite sliding and geometrical non linearities is taken into account. The finite element type is C3D20R (Twenty-node brick element with reduced integration). The mesh density is rather homogeneous and is depicted in figure 4. The displacement at mid span is imposed in order to get the displacement magnitude observed in the experiment (about $20 \mathrm{~cm}$ ). The material is represented by an orthotropic constitutive relation in the elastic domain. The non linear domain is described by an isotropic $J_{2}$ plastic criterion with isotropic work hardening. The non linear part is described by classical plasticity theory which is rather adapted to metallic materials and not to wood materials. The main purpose of this part is to propose a FE model able to develop non linear regimes for checking the ability of the identification method to capture the $M-\chi$ on a virtual test. The flowchart of the validation process is proposed in Figure $2 \mathrm{~b}$.

The material elastic parameters are inspired from Guitard (1989) where several wood species are described. These classical input parameters had been obtained for low moisture content (about 12\%) which corresponds to dry wood state. This set of inputs parameters have been used within the refined FE model in order to validate the identification method. Implicitly, it is assumed that the method is also valid in the case of green wood characterization. Two tree species have been considered (beech and thuyas). Table 2 sums up all the parameters involved where the following relations exist : $E_{R}=-\frac{1}{s_{11}}$, $E_{T}=-\frac{1}{s_{22}}, E_{L}=-\frac{1}{s_{33}}, \nu_{R L}=\nu_{13}=-\frac{s_{31}}{s_{11}}, \nu_{T L}=\nu_{23}=-\frac{s_{23}}{s_{22}}$ and $\nu_{R T}=\nu_{12}=-\frac{s_{12}}{s_{11}}$.

\section{Results}

\subsection{Identification method sensitivity}

The sensitivity of the identification method to the input parameters has been assessed for results from the FE model in the case of thuyas. The main parameters influencing the curvature derivation are first the continuity conditions between polynomial of the three fitting intervals $\left(C^{o}\right.$ or $\left.C^{1}\right)$ and the order of the polynomial $\left(x^{2}\right.$ or $\left.x^{3}\right)$. Two errors are defined in the following. The first one underlines the difference between the fit and the fitted curve and is defined as 


\begin{tabular}{|c||c|c|c|}
\hline Parameter & Beech & Thuyas & Units \\
\hline \hline$E_{R}$ & 2040 & 649 & $\mathrm{MPa}$ \\
$E_{T}$ & 867 & 287 & $\mathrm{MPa}$ \\
$E_{L}$ & 14100 & 3540 & $\mathrm{MPa}$ \\
$G_{R T}$ & 500 & 53 & $\mathrm{MPa}$ \\
$G_{R L}$ & 1850 & 746 & $\mathrm{MPa}$ \\
$G_{L T}$ & 980 & 663 & $\mathrm{MPa}$ \\
$-\frac{1}{s_{12}}$ & 2810 & 1050 & $\mathrm{MPa}$ \\
$-\frac{1}{s_{23}}$ & 30400 & 10400 & $\mathrm{MPa}$ \\
$-\frac{1}{s_{31}}$ & 38600 & 10500 & $\mathrm{MPa}$ \\
\hline$\sigma_{y}$ & 30 & 30 & $\mathrm{MPa}$ \\
$\epsilon_{y}^{p}$ & 0 & 0 & $(-)$ \\
$\sigma_{u}$ & 31 & 31 & $\mathrm{MPa}$ \\
$\epsilon_{u}^{p}$ & 0.35 & 0.35 & $(-)$ \\
\hline
\end{tabular}

TABLE 2 - Parameters related to FE models describing the elastic and plastic behavior of the material.

$$
\xi^{f i t}=\sqrt{\frac{\sum_{i}\left(X_{i}-X_{i}^{f i t}\right)^{2}}{\sum_{i} X_{i}^{2}}} \times 100
$$

where $X_{i}$ are the fitted values and $X_{i}^{f i t}$ the corresponding fit values.

The second one described the adequacy of the SDOF with the FE model in terms of force-displacement curve and is defined such as $\xi^{S D O F}=\frac{A^{S D O F}-A^{F E A}}{A^{F E A}}$ where $A^{F E A}$ (resp. $A^{S D O F}$ ) is the area under the Force-Displacement curve of the SDOF (resp. FE model).

Figure 5 presents the evolution of both errors as a function of the length of the middle fitting interval $\left(L_{2}^{f i t} / \phi_{\text {mean }}\right)$. In figure 5 a it can be noted that $\xi_{f i t}$ remains very small for all considered situations (lower than $0.15 \%)$. For $\xi^{S D O F}$, only the case $\left(C^{1}-x^{3}\right)$ leads to minimize the error magnitude whatever the value of $\frac{L_{2}^{f i t}}{\phi_{\text {mean }}}$. Thus in the following, the continuity condition has been applied on the derivative of $y(x)$, the order of the polynomial is equal to 3 and $\frac{L_{2}^{f i t}}{\phi_{\text {mean }}}=3$.

\subsection{Identification method validation}

Figure 6 presents the results validating the identification method. Two sets of parameters have been considered for thuyas and beech (Table 2). For both cases, FE simulations allows obtaining the F-d curves (Figure 6a-c, red curves). The related $M-\chi$ curves are derived 

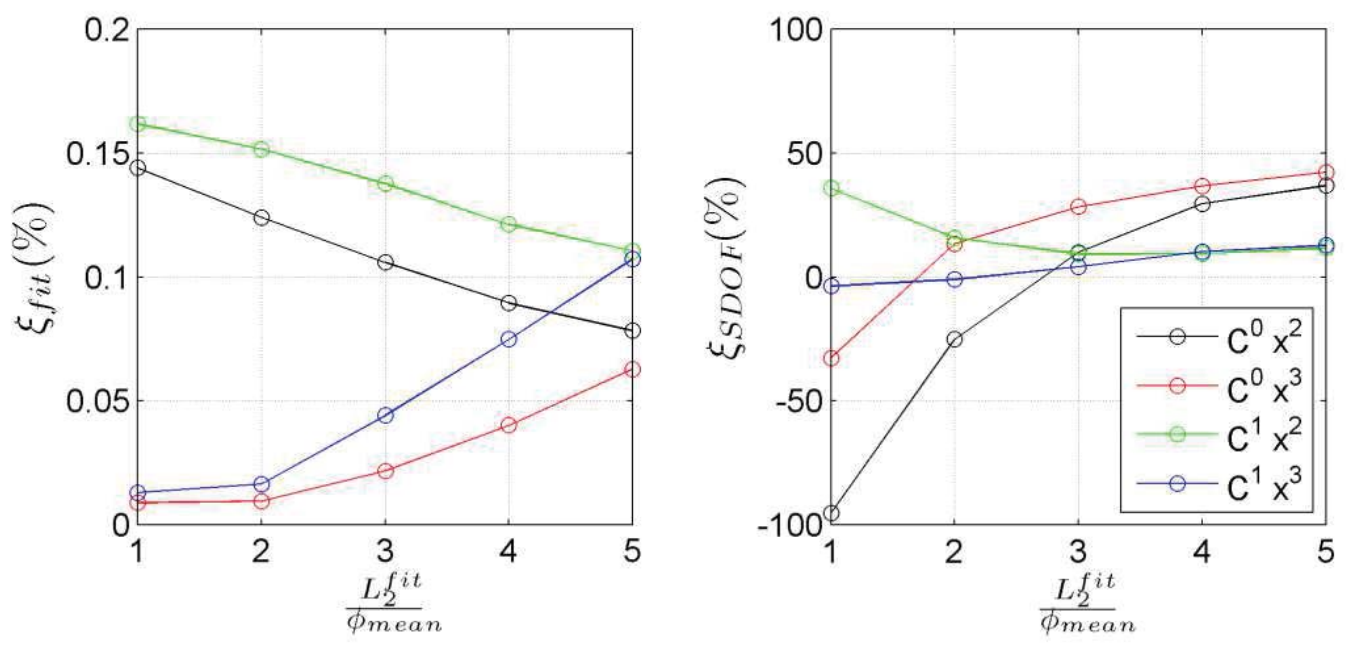

FIGURE 5 - Errors evolutions as a function of the length of the middle fitting interval $\left(L_{2}^{f i t}\right)$ where $\phi_{\text {mean }}=79 \mathrm{~mm}$. $C^{o}$ (resp. $\left.C^{1}\right)$ means the continuity is imposed only (resp. also) on $y^{f i t}$ (resp. $d y^{f i t} / d x$ ) between the fitting intervals. $x^{2}$ (resp. $x^{3}$ ) means the order of the fitting polynomial is 2 (resp. $3)$.

from the identification method (Figure 6b-d, red curves). Knowing the transveral displacement of the longitutinal axis (from the displacement field coming from the FE results), the curvature of the beam at midspan is assessed. The bending moment is obtained by the reaction at the support multiplied by half the distance between the supports.

The results of $\mathrm{FE}$ simulations are used as reference in order to compare it the results coming from the SDOF model. The derived $M-\chi$ curves from the FE model are idealized by tri linear curves and used as an input parameter within the SDOF model in order to perform the SDOF equivalence (Figure 6b-d, black curves). Then it is possible to deduce the predicted F-d curves (Figure 6a-c, blue curves) by the SDOF model. For both cases, a very good agreement can be observed between F-d curves coming from the FE model and the SDOF prediction.

\subsection{Application to fresh wood material}

\subsubsection{M- $\chi$ curves and SDOF equivalence}

From experimental data, 13 tests on fresh wood stems have been considered. The latter allow obtaining the experimental Force-Displacement curve (Figure $7 \mathrm{~b}$ ) and thus deriving the $M-\chi$ curve using the previous identification method (Figure 7a). Applying the SDOF equivalence and for all tests, the experimental $M-\chi$ curves allow a good prediction of 

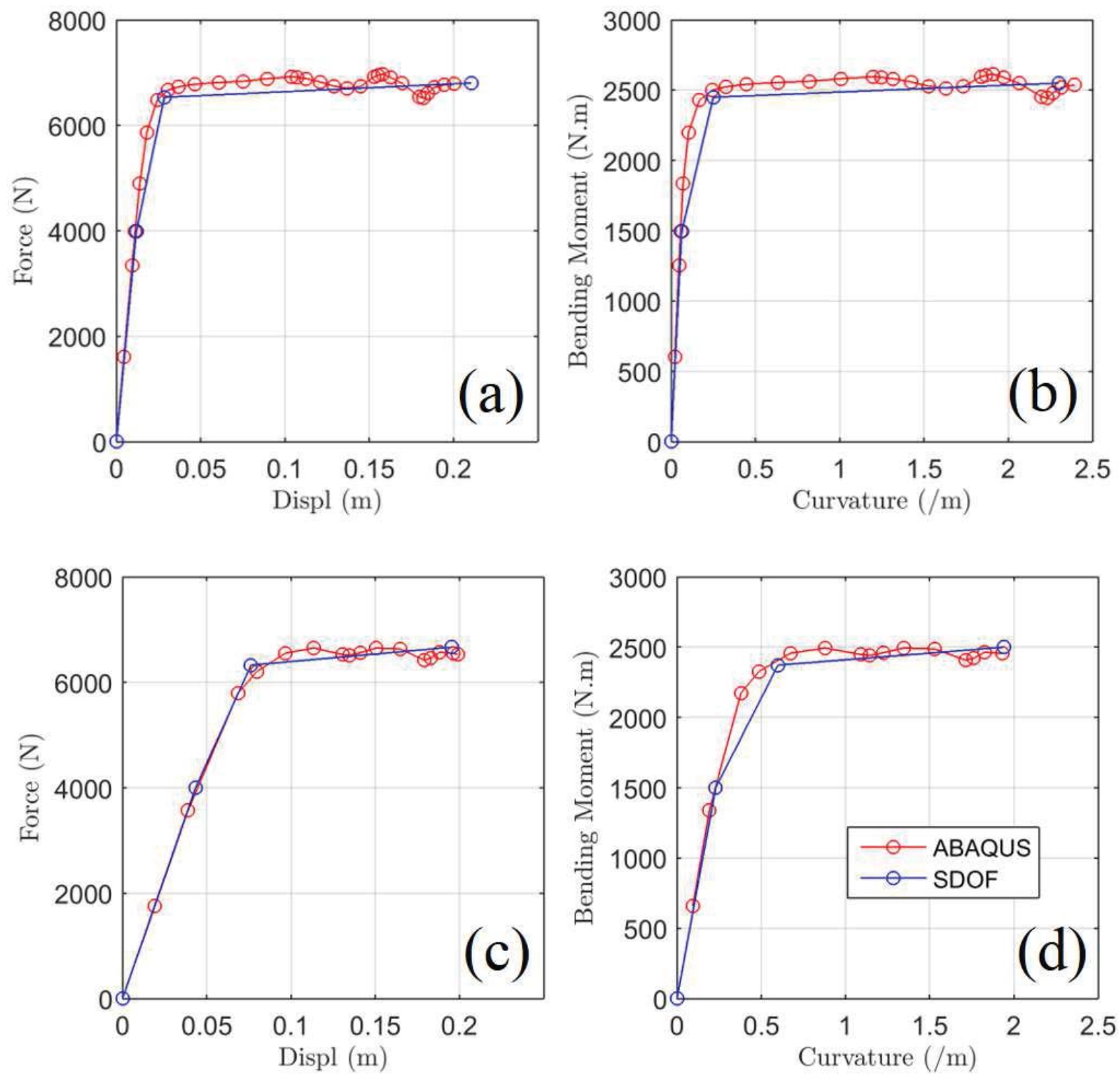

Figure 6 - Validation of the identification method. Comparison between ABAQUS simulations to SDOF predictions. M- $\chi$ curves (b-d) and F-d (a-c) in the case of two wood species (beech (a-b) and thuyas (c-d)). 


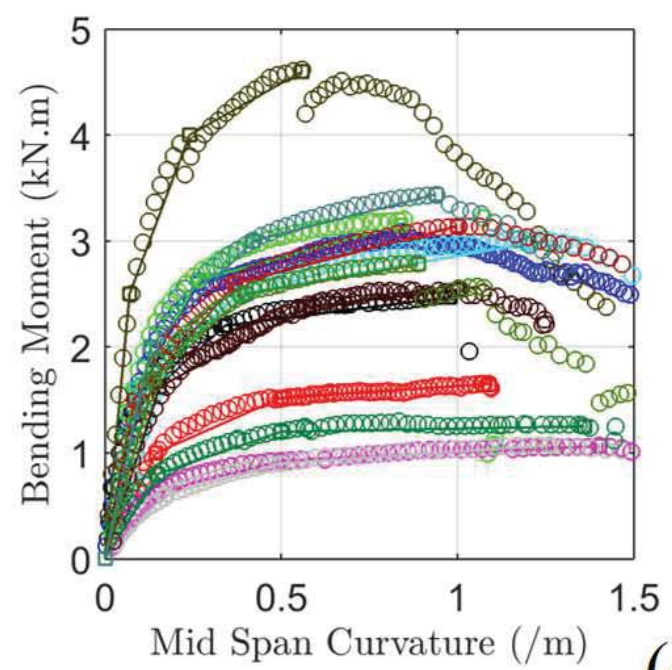

(a)

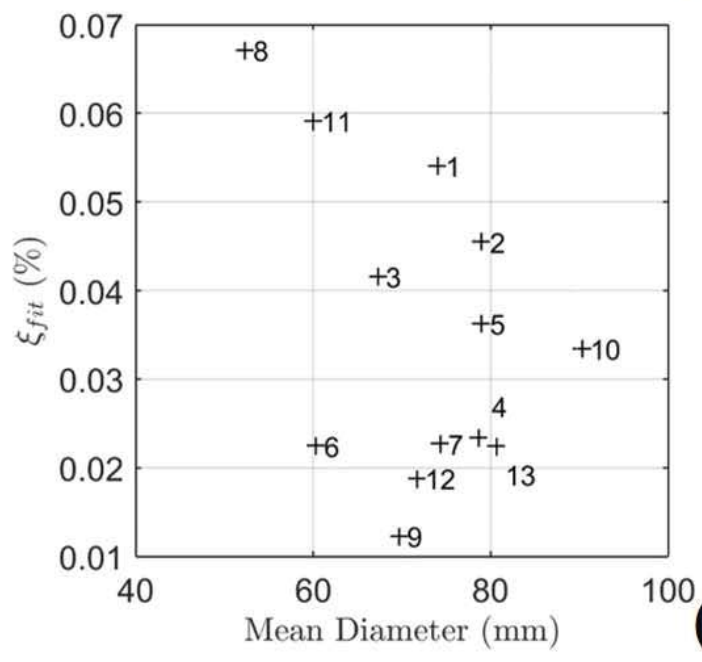

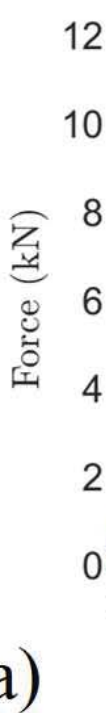

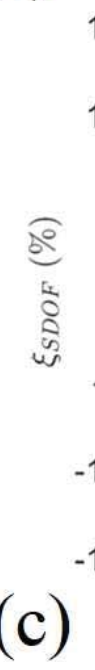

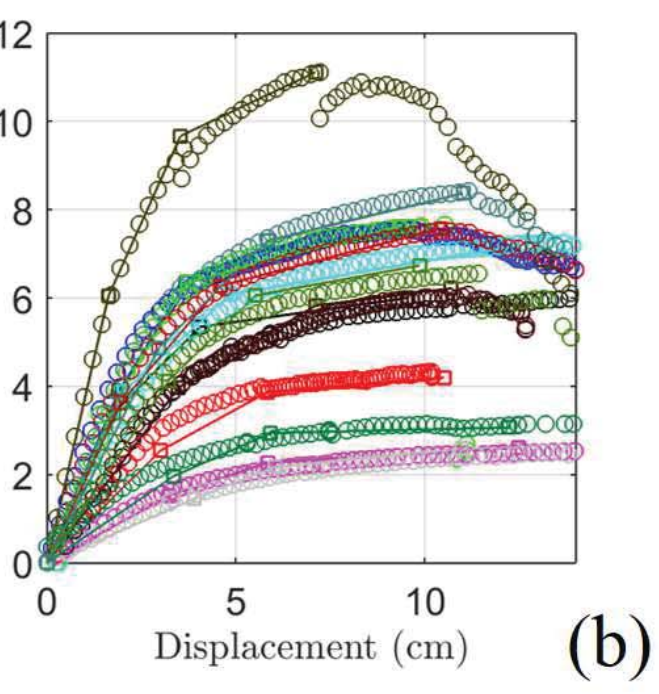

(b)

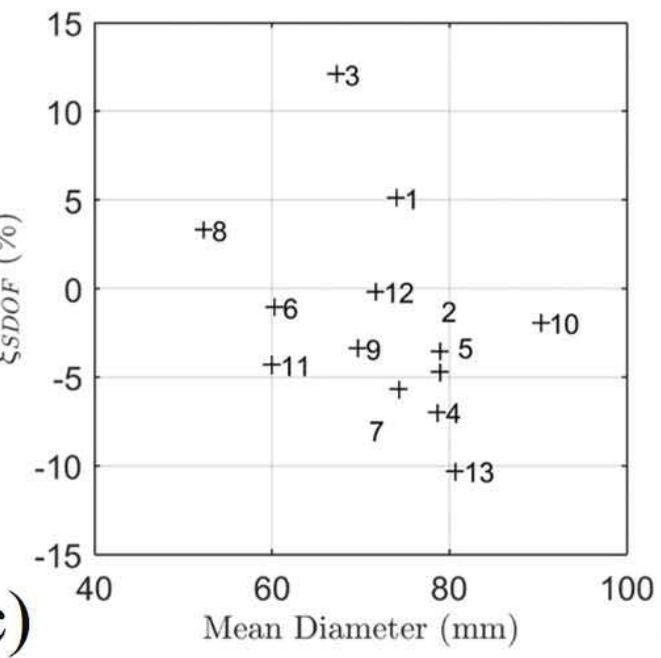

(d)

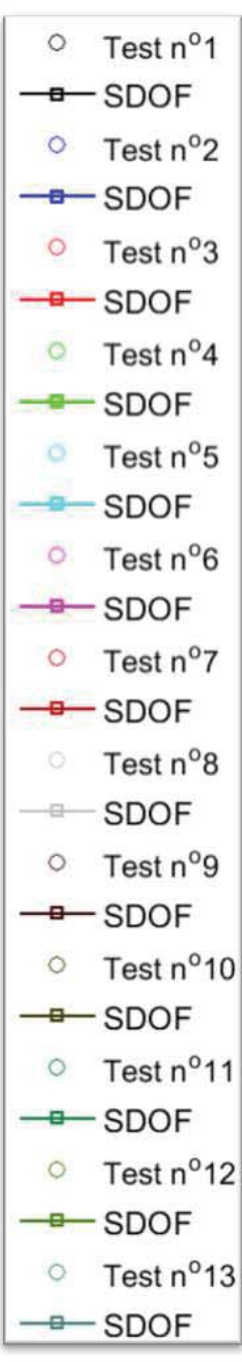

FiguRE 7 - Comparison of experimental results (circle markers) to SDOF predictions (trilinear lines) in terms of $M-\chi$ curves (a) and $F-d$ curves (b). The errors are reported for each test $\xi^{f i t}(\mathrm{c})$ and $\xi^{S D O F}$ (d) 


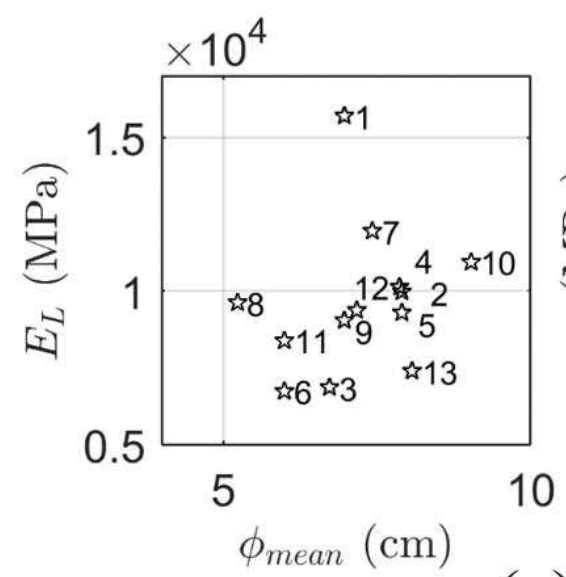

(a)

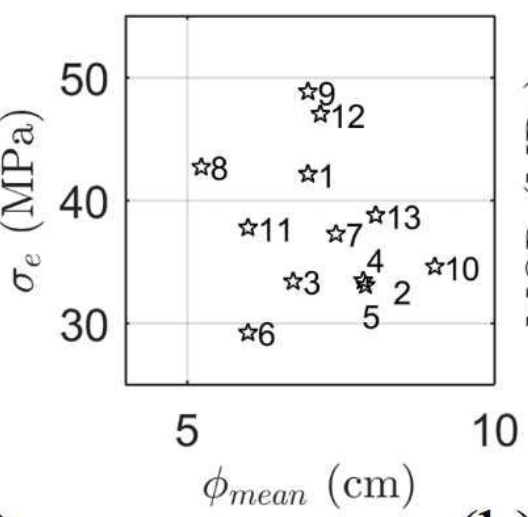

(b)

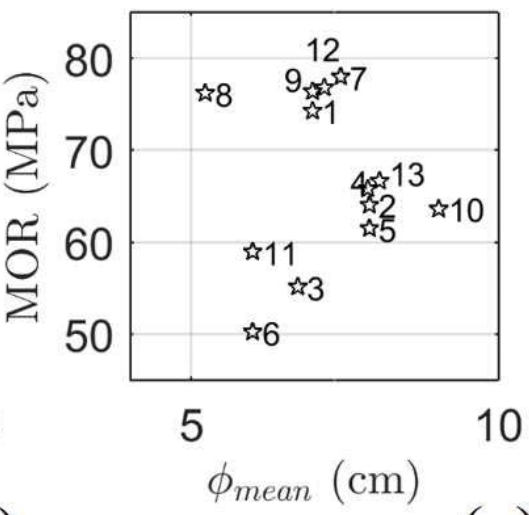

(c)

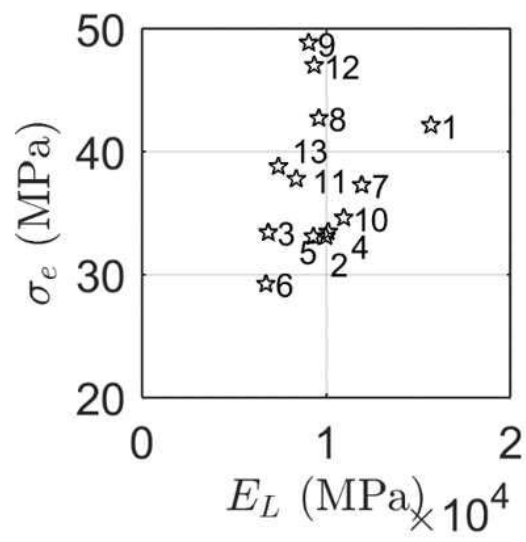

(d)
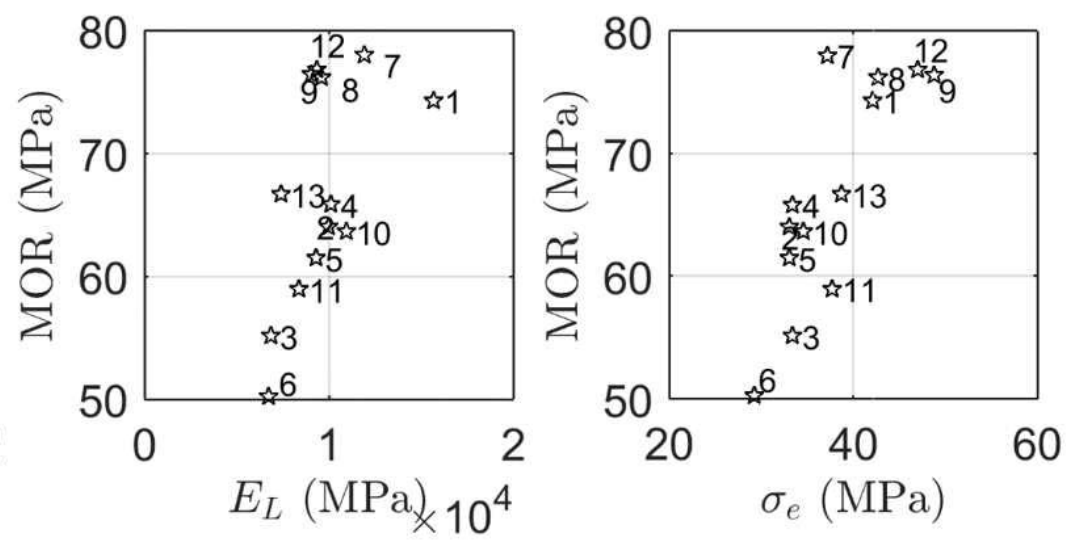

(e)

(f)

FiguRE 8 - Relationships between $\phi_{\text {mean }}, E_{L}, \sigma_{e}$ and $M O R$, of fresh fagus silvatica samples.

the quasi-static response of the stem in terms of Force-Displacement curve. Figure 7c (resp. 7d) depicts the error $\xi^{\text {fit }}$ (resp. $\xi^{S D O F}$ ) related to each tests. The fitting operation involves very little errors. Indeed, $\xi^{\text {fit }}$ is lower than $0.1 \%$ for all tests. Concerning $\xi^{S D O F}$, a maximum of about $10 \%$ is observed which can be mainly attributed to the initial curvature of the stem. The more initial curvature exists, the less the classical beam theory applied. In addition, considering the variability of fresh wood, the identification method is accurate enough.

\subsubsection{Rheological parameters assessment}

Additional information can be extracted from the SDOF equivalence. First, an assessment of the longitudinal Young Modulus $\left(E_{L}\right)$ can be proposed. It can be assumed that the initial stiffness is repre- 
sentative of the elastic response of the beam and can be expressed such as $\bar{K}=E I$ where $I=\pi \phi_{\text {mean }}^{4} / 64$ is the cross-sectional inertia. Next, the elastic stress (resp. the modulus of rupture MOR defined for instance in Hoadley (2000))) can be assess by $\sigma_{e}=\frac{M_{y} \phi_{\text {mean }}}{2 I}$ (resp. $\left.M O R=\frac{M_{u} \phi_{\text {mean }}}{2 I}\right)$ where $M_{y}$ (resp. $\left.M_{u}\right)$ is the bending moment at the beginning of the development of the non linearities (resp. the ultimate bending moment). Table 1 sums up all the derived values.

A significant variability of the mechanical properties can be noted. No clear correlation with $\phi_{\text {mean }}$ or between each parameters can be emphasized (Figure 8). However, these values are in agreement with

previous work carried out on the fresh wood characterization (Olmedo et al. (2015)).

\section{Conclusion}

The study of the mechanical response of fresh wood stems under three points bending tests has enabled to propose an innovative identification method based on DIC and SDOF equivalence methodology. The SDOF equivalence is an interesting approach to model quasi-static and dynamic responses of stems subjected to impact with a very limited computational effort. This kind of models could be easily implemented within rock propagation codes or other models requiring fast computation of fresh wood response to static or dynamic loadings.

In order to perform the SDOF equivalence, the key parameter is the $M-\chi$ curve that develops the considered beam. In this study, the $M-\chi$ curve allows accounting for the material non linearities from a macroscopic point of view (cross-section scale). Due to the large variability of the fresh wood properties, the analysis of results from refined FE modeling of the stem, proposed in order to control the testing conditions, allows validating the identification method. Furthermore, the influence of the parameters (polynomial continuity, fitting interval length and polynomial order) of the method has been studied and underlines than a good approximation is obtained when the underlying physics is correctly described by the interpolation. For three points bending tests, the bending moment evolution along the longitudinal axis is linear. Thus, based on Euler-Bernoulli beam theory, the deflection should correctly be described with a polynomial of order 3 . The better results are observed in this latter case.

The next step will be to use the model in dynamics conditions. The considered loading will be representative of an impact coming from a rockfall. Experimental tests and FE modeling will be used to validate the SDOF equivalence. In a near future, the methodology will be applied for different displacement boundary conditions and impacting load locations. The final objective will be to propose a simple and 
robust SDOF model which can be used within trajectographic codes.

\section{Acknowledgments}

This work has been partially supported by RNVOR (Research network on vulnerability of structures undergoing natural or technological hazards). The authors would like to thank the French national project C2ROP (Chutes de blocs, Risques Rocheux et Ouvrages de Protection

- Rockfalls, Protection devices and rockfall Hazard) and its scientific community to fruitful exchanges on the subject.

\section{Références}

J. Moore. Differences in maximum resistive bending moments of pinus radiata trees grown on a range of soil types. Forest Ecology and Management, 135 :63-71, 2000.

T. Lundstrom, M. Stoffel, and V. Stockli. Fresh-stem bending of silver fir and norway spruce. Tree Physiology, 28 :355-366, 2008.

C. Wessels, F. Malan, and T. Rypstra. A review of measurement methods used on standing trees for the prediction of some mechanical properties of timber. Eur J Forest Res, 130 :881-893, 2011.

D. Sellier, T. Fourcaud, and P. Lac. A finite element model for investigating effects of aerial architecture on tree oscillations. Tree Physiology, 26 :799-806, 2006.

L. Dupuy, T. Fourcaud, P. Lac, and A. Stokes. A generic 3d finite element model of tree anchorage integrting soil mechanics and real root system architecture. American Journal of Botany, 94(9) :1506$1514,2007$.

X. Hu, W. Tao, and Y. Guo. Using fem to predict tree motion in a wind field. Journal of Zhejiang University SCIENCE A, 9(7) : 907-915, 2008.

H. Bentaher, M. Haddar, T. Fakhfakh, and A. Maalej. Finite elements modeling of olive tree mechanical harvesting using different shakers. Trees, 27 :1537-1545, 2013.

K. James, N. Haritos, and P. Ades. Mechanical stability of trees under dynamic loads. American Journal of Botany, 93(10) :1522-1530, 2006. 
L. Dorren, F. Berger, and U. Putters. Real-size experiments and 3-d simulation of rockfall on forested and non-forested slopes. Natural Hazards and Earth System Sciences, 6 :145-153, 2006.

M. Fragiacomo. Long-term behavior of timber-concrete composite beams. ii : Numerical analysis and simplified evaluation. Journal of Structural Engineering, 132 :23-33, 2006.

H. Thoemen and P. Humphrey. Modeling the continuous pressing process for wood-based composites. Wood and fiber science, 35(3) : 456-468, 2003.

T. Alméras, J. Gril, and E. Costes. Bending of apricot tree branches under the weight of axillary growth : test of a mechanical model with experimental data. Trees, $16: 5-15,2002$.

D. Bertrand, F. Bourrier, I. Olmedo, M. Brun, F. Berger, and A. Limam. Experimental and numerical dynamic analysis of a live tree stem impacted by a charpy pendulum. International Journal of Solids and Structures, 50 :1689-98, 2013. doi : 10.1007/s00603-012$0222-5$.

S. Haldar, N. Gheewala, K. Grande-Allen, M. Sutton, and H. Bruck. Multi-scale mechanical characterization of palmetto wood using digital image correlation to develop a template for biologically-inspired polymer composites. Experimental Mechanics, 51 :575-589, 2011.

F. Forsberg, M. Sjodahl, R. Mooser, E. Hack, and P. Wyss. Full three-dimensional strain measurements on wood exposed to threepoint bending : Analysis by use of digital volume correlation applied to synchrotron radiation micro-computed tomography image data. Strains, $46: 47-60,2010$.

J. Ruel, A. Achim, R. Espinoza-Herrera, and A. Cloutier. Relating mechanical strength at the stem level to values obtained from defectfree wood samples. Trees, 24 :1127-1135, 2010.

T. Lundstrom, U. Heiz, M. Stoffel, and V. Stockli. Fresh-wood bending : linking the mechanical and growth properties of a norway spruce stem. Tree Physiology, 27 :1229-1241, 2007.

J. Moore and D. Maguire. Natural sway frequencies and damping ratios of trees : influence of crown structure. Trees, 19 :363-373, 2005.

C. Ciftci, B. Kane, S. Brena, and S. Arwade. Loss in moment capacity of tree stems induced by decay. Trees, $28: 517-529,2014$. 
V. Sebera, L. Praus, J. Tippner, J. Kunecky, J. Cepela, and R. Wimmer. Using optical full-field measurement based on digital image correlation to measure strain on a tree subjected to mechanical load. Trees, 28 :1173-1184, 2014.

R. Milne. Dynamics of swaying of picea stichensis. Tree Physiology, 9 :383-399, 1991.

H. Herajarvi. Static bending properties of finnish birch wood. Wood Science and Technology, 37 :523-530, 2004.

L. Brancheriau, H. Bailleres, and D. Guitard. Comparison between modulus of elasticity values calculated using 3 and 4 point bending tests on wooden samples. Wood Science and Technology, 36 :367383,2002 .

F. Murphy. Commentary on factors affecting transverse vibration using an idealized theoretical equation. Technical report, Res. Note FPLRN-0276, 2000.

L. Dorren, B. Maier, U. Putters, and A. Seijmonsbergen. Combining field and modelling techniques to assess rockfall dynamics on a protection forest hillslope in the european alps. Geomorphology, 57(3) : 151-167, 2004.

I. Olmedo, F. Bourrier, D. Bertrand, D. Toe, F. Berger, and A. Limam. Experimental analysis of the response of fresh wood stems subjected to localized impact loading. Wood Science and Technology, 49 :623$646,2015$.

F. Berger and L. Dorren. Objective comparison of rockfall models using real size experimental data. In Disaster mitigation of debris flows, slope failures and landslides, Universal Academy Press, Inc., pages 245-252, 2006.

F. Bourrier, N. Eckert, F. Nicot, and F. Darve. Bayesian stochastic modeling of a spherical rock bouncing on a coarse soil. Nat. Hazards Earth Syst. Sci., 9 :831-846, 2009.

J. Biggs. Introduction to structural dynamics. McGraw-Hill, 1964.

K. Schellenberg. On the design of rockfall protection galleries. $\mathrm{PhD}$ thesis, ETH Zurich, 2008.

K. Schellenberg, N. Kishi, and H. Kon-no. Analytical model for rockfall protection galleries - a blind prediction of test results and conclusion. Applied Mechanics and Materials, 82 :722-727, 2011. 
D. Bertrand, F. Kassem, F. Delhomme, and A. Limam. Reliability analysis of an rc member impacted by a rockfall using a nonlinear sdof model. Engineering Structures, 89 :93-102, 2015.

N. Tardif and S. Kyriakides. Determination of anisotropy and material hardening for aluminum sheet metal. International Journal of Solids and Structures, $69((25)): 3496-3506,2012$.

D. Guitard. Mécanique du matériau bois et composites. Editions Cépaduès, 1989.

B. Hoadley. Understanding wood. The Taunton Press, 2000. 